\title{
ESTRUTURA POPULACIONAL, PADRÃO ESPACIAL E ESTOQUE DE CARBONO EM BRACATINGAIS NO PLANALTO SUL CATARINENSE
}

\author{
Paula Iaschitzki Ferreira ${ }^{1 *}$, Juliano Pereira Gomes ${ }^{1}$, Lilian Iara Bet Stédille², Marcos Felipe Nicoletti ${ }^{2}$, \\ Roseli Lopes da Costa Bortoluzzi ${ }^{3}$, Adelar Mantovani ${ }^{3}$ \\ ${ }^{1}$ Universidade do Estado de Santa Catarina, Programa de Pós-graduação em Ciências Agrárias, Lages, Santa Catarina, Brasil - \\ paulaiaschitzki@hotmail.com*,julianopgomes@yahoo.com.br \\ ${ }^{2}$ Universidade do Estado de Santa Catarina, Programa de Pós-graduação em Engenharia Florestal, Lages, Santa Catarina, Brasil - \\ lika_stedille@hotmail.com \\ ${ }^{3}$ Universidade do Estado de Santa Catarina, Departamento de Engenharia Florestal, Lages, Santa Catarina, Brasil - \\ marcos.nicoletti@udesc.br, rosebortoluzzi@gmail.com,montovani.a@gmail.com
}

Recebido para a publicação: 29/05/2015 - Aceito para a publicação: 18/03/2016

\begin{abstract}
Resumo
O conhecimento de aspectos relacionados ao comportamento de populações naturais é premissa básica para elaboração de tecnologias adequadas para viabilizar o manejo e conservação de uma espécie. Objetivou-se investigar a estrutura populacional e a distribuição espacial, assim como estimar a biomassa aérea, teor de carbono e a quantidade de $\mathrm{CO}_{2}$ equivalente removido da atmosfera pela biomassa aérea de populações de Mimosa scabrella Benth. com diferentes idades, inseridas em áreas de floresta secundária. Foram alocadas três unidades amostrais, com dimensões de 40x40 m, em quatro locais distintos, totalizando 1,92 ha de área amostral, onde foram calculados os valores de densidade relativa dos indivíduos nas categorias regenerantes (DAP $<5 \mathrm{~cm}$ ) e adultos (DAP $\geq 5 \mathrm{~cm}$ ). O padrão de distribuição espacial foi calculado pelo índice de Morisita para as diferentes populações e a quantidade de $\mathrm{CO}_{2}$ equivalente pela estimativa do carbono total. A estrutura e o padrão de distribuição espacial de M. scabrella são compatíveis aos resultados registrados para outras espécies pioneiras (estádio inicial $=$ agregado; estádio avançado $=$ aleatório). Os maiores valores médios de biomassa, carbono total e $\mathrm{CO}_{2}$ equivalente registrados foram 91,4, 40,1 e 147,2 t.ha-1 respectivamente. As populações de $M$. scabrella demonstram potencialidades de prestação de serviço ambiental no que tange o sequestro e estocagem de carbono, além de contribuírem para o aporte de carbono no solo e serapilheira.

Palavras-chave: Mimosa scabrella Benth.; espécie pioneira; floresta secundária; sequestro de carbono.
\end{abstract}

\begin{abstract}
Population structure, spatial pattern and carbon stock in bracatingais populations of different ages in the Southern Pateau of Santa Catarina. The knowledge related to the behavior of natural populations is basic for development of suitable technologies to enable the management and conservation of a species. This study aimed to investigate the population structure and spatial distribution, as well as estimate the biomass, carbon content and the amount of $\mathrm{CO}_{2}$ removed from the atmosphere by the equivalent biomass populations of Mimosa scabrella Benth. inserted in the secondary forest of different ages. Three sample units were allocated, with dimensions of 40x40 m, totaling 1.92 ha sampling area, which was calculated on the density values of individuals in regenerating categories $(\mathrm{DBH}<5 \mathrm{~cm}$ ) and adults $(\mathrm{DBH} \geq 5 \mathrm{~cm})$. The spatial distribution pattern was calculated by Morisita index for the different populations and the equivalent amount of $\mathrm{CO}_{2}$ the estimated total carbon. The structure and spatial distribution pattern of $M$. scabrella are compatible to the results recorded in other pioneer species. The populations of $M$. scabrella demonstrate potential to provide environmental services, especially in relation to carbon capture and storage.

Keywords: Mimosa scabrella Benth.; pioneer species; secondary forest; carbono sequestration.
\end{abstract}

\section{INTRODUÇÃOO}

A Floresta Ombrófila Mista (FOM), formação típica do Planalto Catarinense, apresenta apenas $24,4 \%$ da sua área coberta por florestas, sendo estas constituídas por fragmentos de florestas secundárias, em estádio médio e avançado, onde são raríssimos os remanescentes de florestas primárias, conforme informações do Inventário Florístico Florestal de Santa Catarina (SEVEGNANI et al., 2013). Entretanto, diante de um cenário de mudança no clima global, as florestas têm recebido notoriedade pelo seu importante papel na remoção do $\mathrm{CO}_{2}$ atmosférico (LARKIN et al., 2014). Desta forma, o pagamento por serviços ambientais no Brasil pode ser considerado uma excelente oportunidade diante das pressões antrópicas exercidas sobre as florestas, surgindo como importante mecanismo para proteção e restabelecimento ambiental.

FLORESTA, Curitiba, PR, v. 46, n. 2, p. 227 - 234, abr. / jun. 2016.

Ferreira, P. I. et al.

ISSN eletrônico 1982-4688

DOI: $10.5380 /$ rf.v46i2.41584 
Mimosa scabrella Benth é uma Fabaceae, da subfamília Mimosoideae, popularmente conhecida como bracatinga, nativa e endêmica do Brasil. Apresenta ampla distribuição geográfica, ocorrendo em todos os estados da região Sul e parte do Sudeste, nos estados de Minas Gerais, Rio de Janeiro e São Paulo (DUTRA; MORIM, 2015). Pertencente ao grupo ecológico das pioneiras ocorre principalmente em formações secundárias de clareiras naturais ou antrópicas da FOM, em destacada abundância, substituindo gradativamente as espécies herbáceas e arbustivas dos estádios iniciais da sucessão. Atualmente, é manejada principalmente para fins energéticos na região metropolitana de Curitiba (PR) (SOUZA et al., 2013) e região noroeste do Planalto Catarinense (STEENBOCK et al., 2011).

Apesar da inexpressiva utilização de suas potencialidades, a bracatinga apresenta amplo espectro de produtos madeiráveis e não madeiráveis, como aproveitamento de madeira serrada, peças torneadas, aglomerados, compensados, varas para olericultura, celulose, construção civil e, ainda, como planta apícola e forrageira (CARPANEZZI et al., 1997; MACHADO et al., 2006; URBANO et al., 2008). Acrescenta-se ainda aspectos relacionados aos potenciais da espécie na restauração ambiental e na fixação de carbono, sendo este último, importante na viabilização de créditos de carbono.

A concepção de tecnologias que visam o uso e conservação de uma espécie são fundamentadas no conhecimento de aspectos relacionados ao comportamento de populações naturais. Desta forma, informações relacionadas à estrutura populacional além de descrever importantes características e probabilidades de projeção através do tempo (LIMA; LEÃO, 2013), podem ser utilizadas para compreensão da sucessão florestal e também fornecer características ecofisiológicas das espécies (SOUZA; JESUS, 1994). Da mesma forma, o estudo do padrão de distribuição espacial de espécies dentro da floresta refletirá a combinação de fatores bióticos e abióticos, que regem a dinâmica dos processos ecológicos da espécie dentro da floresta (SILVA et al., 2008).

Assim, objetivou-se investigar a estrutura populacional e a distribuição espacial de M. scabrella em áreas de floresta secundária com diferentes idades, e avaliar a quantidade de $\mathrm{CO}_{2}$ equivalente removido da atmosfera pela biomassa aérea da espécie. Especificamente buscou-se responder as seguintes questões sobre a espécie: $i$ ) Há diferenças na distribuição diamétrica de populações em diferentes idades, para categorias adultos e regenerantes, sob influência de ambiente montano e altomontano? ii) O padrão de distribuição espacial sofre alterações durante o desenvolvimento da população, em condições de ambiente montano e altomontano? iii) Populações da espécie apresentam potencialidades no que tange a prestação de serviços ambientais por meio do sequestro e estocagem de carbono?

\section{MATERIAL E MÉTODOS}

O estudo foi realizado em fragmentos remanescentes, com presença de populações de $M$. scabrella, localizadas no Planalto Sul Catarinense. Como forma de abranger um gradiente de idade entre as populações, as áreas foram previamente avaliadas com base em entrevistas aos proprietários e verificação em sequências de imagens aéreas (Google Earth). A partir desta análise prévia, foram selecionadas populações com quatro, sete e nove anos, localizadas nos municípios de Bocaina do Sul, Ponte Alta e Lages, com altitude média de $880 \mathrm{~m}$ s.n.m., que de acordo com IBGE (2012) são classificadas como formações de Floresta Ombrófila Mista Montana (FOM-M) e; uma quarta população, também com nove anos, situada no município de Urupema com altitude de aproximadamente 1.425 m s.n.m, a qual é classificada como Floresta Ombrófila Mista Altomontana (FOM-A).

O tipo de solo predominante nas áreas de estudos são Cambissolos (EMBRAPA, 2013), a temperatura média anual é de $14,1^{\circ} \mathrm{C}$ (Urupema) e $16,6^{\circ} \mathrm{C}$ (demais municípios), precipitação média anual está entre $1.634 \mathrm{~mm} /$ ano (Urupema) e $1.441 \mathrm{~mm} /$ ano (Lages) e próxima aos $1.500 \mathrm{~mm} /$ ano (demais municípios), o clima, pela classificação de Köppen, é do tipo Cfb (CLIMATE, 2015).

Em cada área de estudo (população), foram alocadas três unidades amostrais de forma aleatória, com dimensões de $40 \times 40 \mathrm{~m}\left(1.600 \mathrm{~m}^{2} /\right.$ unidade amostral $)$, subdividas em sub-unidades de $10 \times 10 \mathrm{~m}$, totalizando 0,48 ha de área de amostral em cada população. De acordo com o diâmetro à altura do peito (DAP) os indivíduos foram classificados em Adultos (DAP $\geq 5 \mathrm{~cm}$ ) e Regenerantes (DAP $<5 \mathrm{~cm}$ e altura $\geq 10 \mathrm{~cm}$ ). Para os indivíduos adultos foi mensurada a circunferência à altura do peito (CAP) e para regenerantes o diâmetro a altura do colo (DAC), usando fita graduada e paquímetro, respectivamente. Para as árvores que eram bifurcadas foram mensuradas as medidas de CAP ou DAC de todos os fustes, e obtido o diâmetro equivalente por meio da raiz da soma dos diâmetros ao quadrado.

A densidade de plantas foi avaliada de forma gráfica e descritiva para cada categoria (adultos e regenerantes). Também foram elaborados histogramas de frequência das classes de diâmetro para o conjunto total de indivíduos adultos e regenerantes, distribuídas em intervalos de dois centímetros de maneira empírica.

A estrutura espacial das populações dentro das unidades amostrais foi verificada pelo índice de Morisita Padronizado (Id), o qual é pouco influenciado pelo tamanho da unidade amostral. O cálculo deste índice foi realizado com auxílio do Programa R Studio, onde se obtém o Id, conforme os seguintes arranjos espaciais: aleatório $(-0,5<\mathrm{Id}<0,5)$, agregado $(\mathrm{Id}>0,5)$ e uniforme $(\mathrm{Id}<0,5)$. 
Para estimativa do estoque de biomassa e carbono das árvores adultas foi empregado o método nãodestrutivo, devido restrições de ordem legal e operacional, onde foram avaliados apenas a biomassa do fuste com casca e não de outros compartimentos florestais, como galhos e folhas. Assim, utilizaram-se equações já ajustadas por outros autores para esta espécie (Tabela 1), em que a seleção da equação mais adequada foi baseada no melhor coeficiente de determinação $\left(\mathrm{R}^{2}\right)$, análise gráfica de resíduos e por terem características similares a área de estudo. Optou-se pela adoção das equações propostas por Baggio et al. (1995) e Urbano et al. (2008). Em ambos os casos, os autores avaliaram indivíduos de Mimosa scabrella com idade variando entre quatro e onze anos e DAP $=4$ a $35 \mathrm{~cm}$. Devido à baixa representatividade de árvores adultas, a população de quatro anos foi excluída para fins de mensuração de biomassa e carbono, em função da inviabilização na utilização das equações propostas na bibliografia utilizada.

Para a conversão média do teor de carbono encontrado em cada população estudada, para toneladas de $\mathrm{CO}_{2}$ equivalente, a qual é a principal medida de serviço ambiental de sequestro e estocagem de carbono, empregada nas transações de mercado de créditos de carbono, foi adotado o fator de conversão igual a 3,67, que corresponde ao peso atômico do $\mathrm{CO}_{2}$ (44) dividido pelo peso atômico do carbono (12), conforme IPCC (2006).

Tabela 1. Equações para estimativa de peso da biomassa e carbono total da parte aérea de árvores de Mimosa scabrella Benth. Onde: dap = diâmetro à altura do peito $(\mathrm{cm})$; Ps = peso seco de biomassa total individual $(\mathrm{kg}) ; \mathrm{Pc}=$ peso de carbono total individual $(\mathrm{kg})$.

Table 1. Equations for weight estimate biomass and total carbon shoots of Mimosa scabrella Benth trees. Where: dap = diameter at breast height $(\mathrm{cm})$; Ps = dry weight of individual total biomass $(\mathrm{kg}) ; \mathrm{Pc}=$ total individual weight of carbon $(\mathrm{kg})$.

\begin{tabular}{|c|c|c|c|}
\hline Variável & Equação & $\mathbf{R}^{2}$ & Referência \\
\hline Biomassa & Ps $=0,2101 \cdot$ dap $^{2,2499}$ & 0,995 & Baggio et al. (1995) \\
\hline Carbono & $\mathrm{Pc}=-4,0804+0,2075 \cdot \mathrm{dap}^{2}$ & 0,949 & Urbano et al. (2008) \\
\hline
\end{tabular}

\section{RESULTADOS}

Para árvores adultas as estatísticas descritivas (Tabela 2) demonstram que a população mais jovem (quatro anos) obteve a maior homogeneidade diamétrica (desvio padrão $(\sigma)=1,13$ ). Para a regeneração, a população de nove anos (FOM-M) apresentou a maior variação nos valores de DAC $(\sigma=5,36)$.

Tabela 2. Estatística descritiva das diferentes populações de Mimosa scabrella Benth. Onde: DAP = Diâmetro à altura do peito; DAC = Diâmetro à altura do colo.

Table 2. Descriptive statistics of the different populations of Mimosa scabrella Benth. Where: DAP = diameter at breast height; $\mathrm{DAC}=$ diameter at height soil.

\begin{tabular}{|c|c|c|c|c|}
\hline \multirow{2}{*}{ Variável } & \multicolumn{4}{|c|}{ Populações de Mimosa scabrella Benth. } \\
\hline & 4 anos* $^{*}$ & 7 anos* & 9 anos* & 9 anos** \\
\hline \multicolumn{5}{|l|}{$(\mathrm{DAP} \geq 5 \mathrm{~cm})$} \\
\hline DAP mínimo $(\mathrm{cm})$ & 5,10 & 5,00 & 5,10 & 5,00 \\
\hline DAP máximo (cm) & 9,80 & 36,6 & 24,80 & 28,60 \\
\hline DAP médio $(\mathrm{cm})$ & 6,10 & 10,3 & 12,20 & 10,10 \\
\hline Desvio padrão DAP $(\mathrm{cm})$ & 1,13 & 4,20 & 3,80 & 3,40 \\
\hline Densidade (ind.ha ${ }^{-1}$ ) & 134 & 1.403 & 2.084 & 803 \\
\hline \multicolumn{5}{|l|}{$(\mathrm{DAP}<5 \mathrm{~cm})$} \\
\hline DAC mínimo $(\mathrm{cm})$ & 0,15 & 1,00 & 3,81 & 1,90 \\
\hline DAC máximo $(\mathrm{cm})$ & 11,2 & 6,82 & 19,5 & 4,24 \\
\hline DAC médio $(\mathrm{cm})$ & 1,53 & 3,74 & 12,2 & 7,10 \\
\hline Desvio padrão DAC $(\mathrm{cm})$ & 1,27 & 1,05 & 5,36 & 0,99 \\
\hline Densidade (ind.ha ${ }^{-1}$ ) & 11.541 & 631 & 306 & 62 \\
\hline
\end{tabular}

*Floresta Ombrófila Mista Montana; **Floresta Ombrófila Mista Altomontana.

Com exceção da população mais jovem (quatro anos), em que 98\% dos indivíduos pertencem à classe de regenerantes, as demais áreas apresentaram redução na participação de indivíduos desta classe. A população com sete anos apresentou em média 31\% dos indivíduos regenerantes e, em ambas as áreas de nove anos, esta classe foi representada por menos de $13 \%$ do total dos indivíduos. Nas áreas com influência do ambiente 
montano foi registrada para a densidade total (adultos e regenerantes) 11.675, 2.034 e 865 ind.ha $^{-1}$, respectivamente para as populações com quatro, sete e nove anos. Para a população com nove anos com influência do ambiente altomontano, a densidade foi mais próxima àquela registrada para a população de sete anos, com 2.390 ind.ha $^{-1}$.

Em relação à distribuição diamétrica foi possível observar diferenças entre as categorias adulta e regenerante (Figura 1), assim como entre as populações. Na população mais jovem (quatro anos), em ambas as categorias, observou-se maior concentração dos indivíduos nas primeiras classes diamétricas. Entretanto, nas populações com sete e nove anos com influência do ambiente montano, para a categoria regenerantes, observouse menor número de indivíduos na primeira classe em relação à segunda e distribuição irregular nas classes subsequentes. A categoria adulta destas populações se caracterizou pelo acúmulo de indivíduos nas classes intermediárias, ou seja, com comportamento tendendo a normalidade.
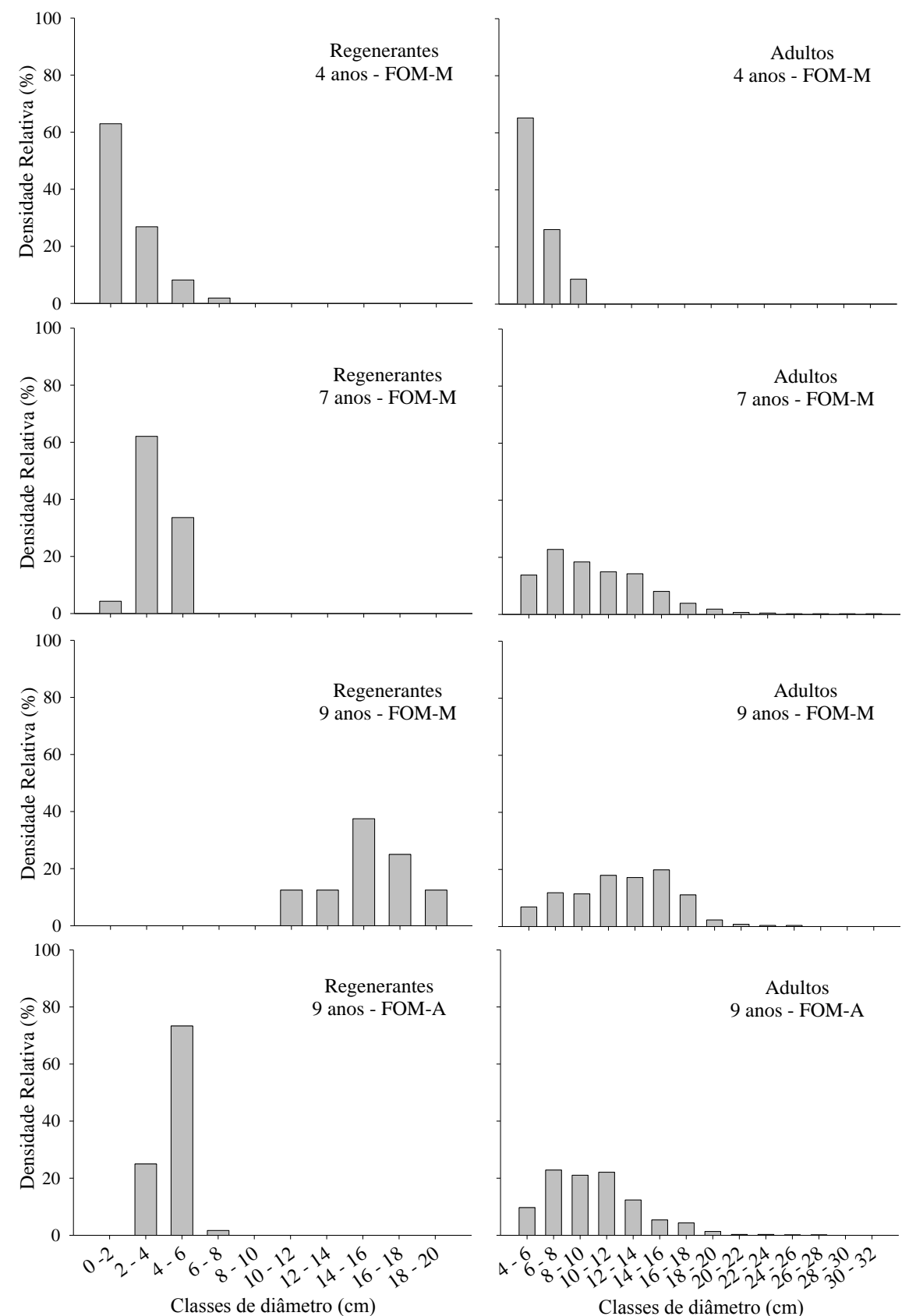

Figura 1. Distribuição diamétrica de indivíduos das categorias regenerantes e adultos de Mimosa scabrella Benth. em populações naturais com diferentes idades localizadas no Planalto Sul Catarinense.

Figure 1. Diameter distribution of individuals of regenerating categories and adult Mimosa scabrella Benth. in natural populations of different ages located in the Southern Plateau of Santa Catarina. 
Apenas a população com nove anos com influência do ambiente montano apresentou distribuição espacial aleatória $(-0,5<\mathrm{Id}<0,5)$, já as demais populações, bem como, àquela com nove anos com influência do ambiente altomontano, apresentaram valores que caracterizam padrão agregado de distribuição (Id $>0,5)$.

Os maiores valores médios de estoque de biomassa, carbono e em $\mathrm{CO}_{2}$ equivalente foram registrados na população de nove anos, com influência do ambiente altomontano, com valores de 91,4, 40,1 e 147,2 t.ha ${ }^{-1}$ respectivamente (Figura 2).

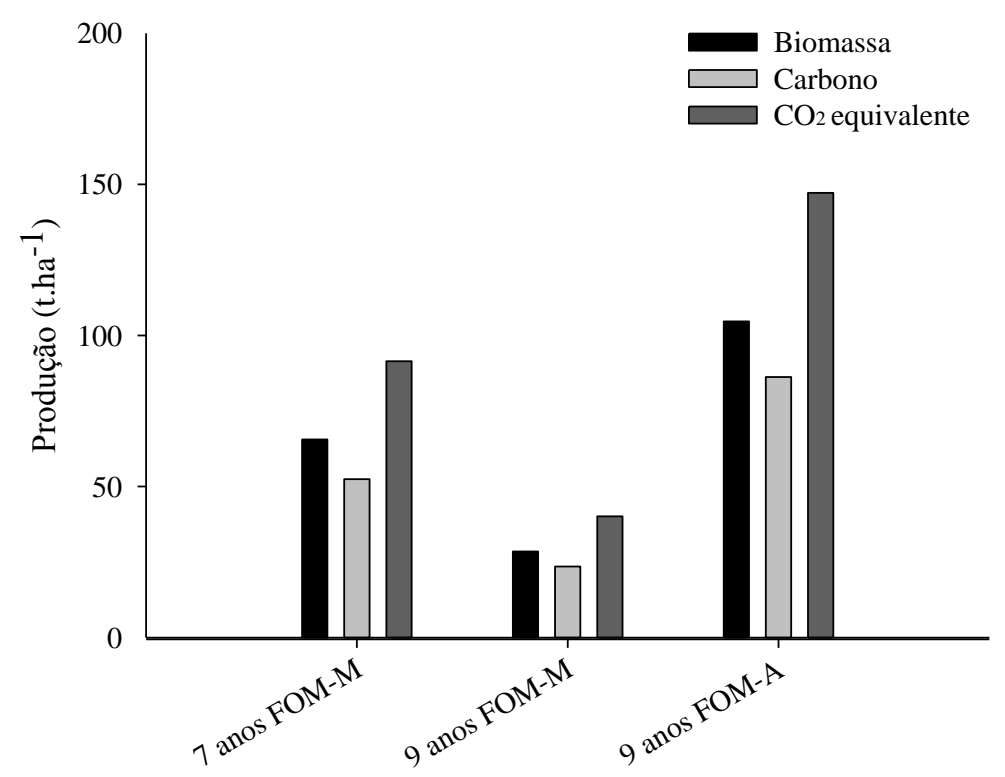

Figura 2. Estimativas de biomassa, carbono total e $\mathrm{CO}_{2}$ equivalente (t.ha ${ }^{-1}$ ) na parte aérea de árvores de Mimosa scabrella Benth. em populações naturais com diferentes idades localizadas no Planalto Sul Catarinense.

Figure 2. Biomass estimates, total carbon and $\mathrm{CO}_{2}$ equivalent (t ha-1) in the shoot of Mimosa scabrella Benth. trees in natural populations of different ages located in the Southern Plateau of Santa Catarina.

\section{DISCUSSÃO}

Considerando a necessidade de fonte luminosa para quebra de dormência das sementes de bracatinga, a ausência de novos eventos que culminem na exposição do banco de sementes do solo e germinação destas reduz a possibilidade de ingresso de novos indivíduos. Desta forma, era esperada a redução da participação da categoria regenerantes com o aumento da idade da população de M. scabrella, fato este que aproxima estas populações às características de uma população equiânea. Baggio e Carpenazzi (1997) também evidenciaram a redução da participação dos indivíduos regenerantes estudando uma população de bracatinga com sete anos de idade, onde os autores registraram que menos de $37 \%$ dos indivíduos não atingiram sete centímetros de DAP.

Associado a este aspecto está à redução da densidade com o aumento da idade populacional, que assim como registrado neste estudo, também foi descrito por Machado et al. (2008) e Tonon (1998). A bracatinga regenera-se em abundância após distúrbios que provoquem abertura do dossel, formando um povoamento quase puro, onde pode apresentar até 100.000 ind./ha ${ }^{-1}$ em seu primeiro ano de vida (MACHADO et al., 2006). Entretanto, por tratar-se de uma espécie heliófita, a germinação maciça das sementes de M. scabrella, reduz a luminosidade do subdossel que, assim como mencionado por Carpanezzi et al. (1997), limita a expansão das copas e causa a morte gradativa de muitas plantas. Jardim et al. (2007) em estudo sobre crescimento e mortalidade de espécies arbóreas, atribuíram a grande mortalidade, registrada para a espécie pioneira Jacaranda copaia Aublet, ao grande número de indivíduos regenerando em ambientes que recebiam radiação direta. Desta forma as taxas mais elevadas de mortalidade parecem ser um padrão associado com as espécies que têm maior necessidade de luz; em populações de $M$. scabrella, caracteriza a ocorrência de desbastes naturais, que em um primeiro momento se dá em função da intensidade luminosa.

Em relação à população de nove anos com influência do ambiente altomontano, foi observado densidade próxima à população de sete anos. Resultado possivelmente associado à redução do ritmo de 
crescimento dos indivíduos, ocasionado por baixas temperaturas, baixa incidência de radiação solar e elevada umidade relativa do ar, típica de ambientes altomontanos.

A maior concentração de indivíduos nas primeiras classes diamétricas, observado na população mais jovem (quatro anos), reflete o estágio inicial de desenvolvimento desta população. Entretanto, o comportamento registrado para categoria regenerantes das populações de sete e nove anos, com influência do ambiente montano, evidenciam a necessidade de condições específicas para regeneração. Assim, conforme já discutido o ingresso de novos indivíduos de bracatinga está condicionado à abertura de clareiras e com isso o aumento da luminosidade. Este fato é evidenciado analisando-se a alta concentração de indivíduos adultos nas classes de diâmetro intermediárias, onde a distribuição diamétrica foi unimodal, sendo esta característica de florestas equiâneas (SOUZA; JESUS, 1994), que quando são de ocorrência natural, são homogêneas, com espécies que se regeneram em ciclos (MACHADO et al., 2006), assim como observado para M. scabrella em função da intensidade luminosa. Da mesma forma, Araújo et al. (2006) atribuíram o baixo recrutamento de Cecropia hololeuca Miq. (espécie heliófita), refletido pela distribuição diamétrica tendendo a normalidade e sombreamento produzido pelo dossel, sugerindo ser este o comportamento típico de espécies pioneiras, as quais serão substituídas durante o avanço do processo sucessional.

Desta forma, o amplo desenvolvimento de bracatinga em áreas alteradas, com ausência de formação de banco de plântulas, e posterior redução da densidade de indivíduos ao longo do desenvolvimento da população, confirmam o efeito facilitador de M. scabrella, que estará atuando na melhoria das condições abióticas e assim propiciar condições mais adequadas para estabelecimento e desenvolvimento de espécies mais exigentes em condições edafoclimáticas, oriundas do entorno.

O comportamento da distribuição espacial das populações de $M$. scabrella, avaliadas neste estudo, reflete a síndrome de dispersão autocórica, a qual confere o comportamento agregado nas populações em fases iniciais (quatro e sete anos), assim como àquela pertencente ao ambiente altomontano (nove anos, FOM-A), e padrão aleatório na população em estágio mais avançado de desenvolvimento (nove anos, FOM-M). Assim como observado para os valores de densidade, o padrão espacial agregado registrado para a população pertencente ao ambiente altomontano, reflete à redução da dinâmica populacional. De maneira geral, o comportamento da distribuição espacial apontado para as populações de $M$. scabrella avaliadas neste estudo corrobora com a hipótese da segregação espacial, formulada por Pacala e Levin (1992), onde os autores afirmam que espécies sob competição intraespecífica, em um primeiro momento, se distribuiriam de forma agregada por causa da limitação na dispersão das sementes, mas que ao longo do desenvolvimento e da maior densidade de indivíduos, a alta mortalidade atua diminuindo a agregação. Esta tendência tem sido verificada em outros estudos com espécies iniciais de sucessão, como Cedrela fissilis Vell. e Casearia sylvestris Sw. (MACHADO et al., 2012) e Eremanthus erythropappus (DC.) MacLeish (SILVA et al., 2008).

Os valores de biomassa, registrados no presente estudo para as populações de sete e nove anos com influência do ambiente montano, são compatíveis àqueles registrados por Carpanezzi et al. (1997) em cinco bracatingais com idade de sete anos, na região metropolitana de Curitiba, PR, com valores entre 58,4 e 80,9 t.ha ${ }^{1}$. Em relação aos valores médios de carbono total observou-se redução de aproximadamente $20 \%$ da população de sete para nove anos. Este comportamento também foi registrado por Souza et al. (2013), trabalhando com bracatingais nativos da região metropolitana de Curitiba, PR, onde empregou-se a mesma equação utilizada no presente estudo. Estes autores registraram redução de aproximadamente $90 \%$ do peso de carbono total em um povoamento de seis anos $\left(48,2\right.$ t.ha $\left.{ }^{-1}\right)$ em relação a outro com idade de 14 anos $\left(5,1\right.$ t.ha $\left.{ }^{-1}\right)$. Guedes et al. (2003) em estudo referente a quantificação de carbono armazenado em bracatingais com diferentes idades, verificaram valores de carbono na biomassa de 22, 33, 47 e 61 t.ha $^{-1}$ nas idades de 1, 3, 5 e 8 anos, respectivamente.

Estas diferenças de produção de biomassa e carbono entre os bracatingais, com diferentes idades, estão diretamente relacionadas à densidade populacional e condições edafoclimáticas, as quais as populações estão expostas. Associado a este aspecto, está o maior valor de biomassa, carbono total e carbono equivalente, registrado neste estudo na área de nove anos com influência do ambiente altomontano. Às peculiaridades deste ambiente possivelmente condicionam o ritmo da dinâmica populacional de $M$. scabrella, tornando-a mais lenta. Logo, os efeitos relacionados à competição intraespecífica, como o desbaste natural ainda não são tão intensos, podendo-se verificar este aspecto nos valores de densidade, os quais são semelhantes à população de sete anos no ambiente montano. Corroborando com Koehler et al. (2002), este resultado evidencia que o clima de áreas montanhosas desempenha forte influência sobre a estrutura do componente arbóreo, assim como registrado neste estudo para ecologia de $M$. scabrella, e ainda demonstra a potencialidade das populações desta espécie na prestação de serviço ambiental no que tange o sequestro e estocagem de carbono.

Contudo, é importante ressaltar a importância das populações de $M$. scabrella no que tange a ciclagem de nutrientes, especialmente para o carbono, denotando assim o efeito facilitador desta espécie para recuperação de áreas degradadas. A redução do estoque de carbono em termos de biomassa ao longo do desenvolvimento desta espécie neste e em outros estudos, evidencia o aporte deste elemento para serapilheira e solo, contribuindo para melhoria das condições ambientais das áreas onde estas populações estão inseridas. 


\section{CONCLUSÕES}

- As fases iniciais de desenvolvimento das populações de $M$. scabrella são marcadas pela ocorrência de desbastes naturais, oriundo das pressões impostas pela competição intraespecífica.

- A distribuição diamétrica na população em estádio inicial demonstrou alta concentração de indivíduos nas primeiras classes e, distribuição unimodal nas populações em estádio mais avançado, estando em conformidade com a estrutura de florestas naturais equiâneas.

- O padrão de distribuição espacial de M. scabrella é compatível com aqueles registrados para outras espécies pioneiras, e apresenta alterações durante o desenvolvimento da população, em condições de ambiente altomontano

- As populações de M. scabrella demonstram potencialidades de prestação de serviço ambiental no que tange o sequestro e estocagem de carbono, além de contribuírem para o aporte de carbono no solo e serapilheira.

\section{AGRADECIMENTOS}

Os autores agradecem a empresa Klabin SA e a FAPESC (Fundação de Amparo à Pesquisa e Inovação do Estado de Santa Catarina) pelo apoio financeiro, e ao FUMDES (Fundo de Apoio à Manutenção e ao Desenvolvimento da Educação Superior - Secretaria de Estado da Educação de Santa Catarina) pela concessão da bolsa de doutorado para a primeira autora.

\section{REFERENCIAS}

ARAÚJO, F. S.; MARTINS, S. V.; MEIRA NETO, J. A. A.; LANI, J. L.; PIRES, I. E. Estrutura da vegetação arbustivo-arbórea colonizadora de uma área degradada por mineração de caulim, Brás Pires, MG. Ârvore, Viçosa, v. 30, n. 1, p.107 - 116, 2006.

BAGGIO, A. J.; CARPANEZZI, A. A. Biomassa aérea da bracatinga (Mimosa scabrella Benth.) em talhões do sistema de cultivo tradicional. Boletim de Pesquisa Florestal, Colombo, n. 34, p. 31 - 44, 1997.

BAGGIO, A. J.; CARPANEZZI, A. A.; AYANZ, A. S. Equações estimativas de peso da biomassa aérea da bracatinga (Mimosa scabrella Benth.) na idade de corte. Boletim de Pesquisa Florestal, Colombo, n. 30/31, p.37 - 49, 1995.

CARPANEZZI, A. A.; CARPANEZZI, O. T. B.; BAGGIO, A. J. Manejo de bracatingais. In: CURSO DE MANEJO FLORESTAL SUSTENTAVEL. Tópicos em manejo florestal sustentável. Colombo, EMBRAPACNPF, 1997, $156 \mathrm{p}$.

CLIMATE.DATA.ORG (CLIMATE). Dados climáticos para as cidades mundiais. Disponível em: <http:// http://pt.climate-data.org/>. Acesso em: 16/01/2015.

DUTRA, V. F.; MORIM, M. P. Mimosa in Lista de Espécies da Flora do Brasil. Jardim Botânico do Rio de Janeiro. Disponível em: 〈http://floradobrasil.jbrj.gov.br/jabot/floradobrasil/FB100978>. Acesso em: 13/03/2015.

EMPRESA BRASILEIRA DE PESQUISA AGROPECUÁRIA (EMBRAPA). Sistema brasileiro de classificação de solos. 3. ed. Brasília, 2013, 353 p.

GUEDES, F. A. G.; DEDECEK, R. A.; WISNIEWSKI, C.; MONTOYA VILCAHUAMAN, L. J. Avaliação da Biomassa e Carbono do Sistema Agroflorestal da Bracatinga. In: Anais do II Evento de Iniciação Científica da Embrapa Florestas, Colombo, 2003.

INSTITUTO BRASILEIRO DE GEOGRAFIA E ESTATÍSTICA (IBGE). Manual Técnico da Vegetação Brasileira. 2 ed. revisada e ampliada, 2012, 271p.

INTERGOVERNMENTAL PANEL ON CLIMATE CHANGE (IPCC). Guidelines for National Greenhouse Gas Inventories. Disponível em <http://www.ipcc-nggip.iges.or.jp/public/2006gl.2006> Acesso em: 17 de mai. 2015.

JARDIM, F. C. S.; SERRÂO, D. R.; NEMER, T. C. Efeito de diferentes tamanhos de clareiras, sobre o crescimento e a mortalidade de espécies arbóreas, em Moju-PA. Acta Amazônica, Manaus, v. 37, n. 1, p. 37 47, 2007. 
KOEHLER, A.; GALVÃO, F.; LONGHI, S. J. Floresta Ombrófila Densa Altomontana: aspectos florísticos e estruturais de diferentes trechos da serra do mar. Ciência Florestal, Santa Maria, v. 12, n. 2, p. 27 - 39, 2002.

LARKIN, D. J.; STEFFEN, J. F.; GENTILE, R. M.; ZIRBEL1, C. R. Ecosystem Changes Following Restoration of a Buckthorn-Invaded Woodland. Restoration Ecology, v. 22, p. 89 - 97, 2014.

LIMA, J. P. C.; LEÃO, J. R. A. Dinâmica de crescimento e distribuição diamétrica de fragmentos de florestas nativa e plantada na Amazônia sul ocidental. Floresta e Ambiente, Seropédica, v. 20, n. 1, p. 70 - 79, 2013.

MACHADO, S. A.; BARTOSZECK, A. C. P. S.; FIGUEIREDO FILHO, A.; OLIVEIRA, E. B. Dinâmica da distribuição diamétrica de bracatingais na região metropolitana de Curitiba. Árvore, Viçosa, v. 30, n. 5, p. 759 $768,2006$.

MACHADO, S. M.; AGUIAR, L. P.; FIGUEIREDO FILHO, A.; KOEHLER, H. S. Modelagem do volume do povoamento para Mimosa scabrella Benth. na região metropolitana de Curitiba. Árvore, Viçosa, v. 32, n. 3, p. 465 - 478, 2008.

MACHADO, S. M.; SANTOS, A. A. P.; ZAMIN, N. T.; NASCIMENTO, R. G. M. Distribuição espacial de um fragmento de Floresta Ombrófila Mista Montana. Ciência Rural, Santa Maria, v. 42, n. 6, p. 1013 - 1019, 2012.

PACALA, S. W.; LEVIN, S. A. Biologically generated spatial pattern and the coexistence of competing species. In: TILMAN, D.; KAREIVA, P. (eds). Spatial ecology. University Press, Princeton, New Jersey, USA. 1997, p. 250.

SEVEGNANI, L.; VIBRANS, A. C.; GASPER, A. L. Considerações finais sobre a Floresta Ombrófila Mista em Santa Catarina. In: VIBRANS, A. C.; SEVEGNANI, L.; GASPER, A. L.; LINGNER, D. V. Considerações finais sobre a Floresta Ombrófila Mista em Santa Catarina. Inventário Florístico Florestal de Santa Catarina: Floresta Ombrófila Mista. Blumenau: Edifurb, 2013, 440 p.

SILVA, M. A.; MELLO, J. M.; SCOLFORO, J. R. S.; CZANCK JÚNIOR, L.; ANDRADE, I. S.; OLIVEIRA, A. D. Análise da distribuição espacial da candeia (Eremanthus erythropappus (DC.) MacLeish) sujeita ao sistema de manejo porta-sementes. Cerne, Lavras, v. 14, n. 4, p. 311 - 316, 2008.

SOUZA, R. F.; MACHADO, S. A.; FIGUEIREDO FILHO, A.; KOEHLER, H. S. Modelagem do carbono orgânico total e da lenha por unidade de área para bracatingais nativos. Ciência Florestal, Santa Maria, v. 23, n. 1, p. 117 - 127, 2013.

SOUZA, A. L.; JESUS, R. M. Distribuição diamétrica de espécies arbóreas da Floresta Atlântica: análise de agrupamento. Viçosa, MG: Sociedade de Investigações Florestais. Boletim Técnico, n. 10, p. 30, 1994.

STEENBOCK, W.; SIMINSKI, A.; FANTINI, A. C.; REIS, M. S. Ocorrência da bracatinga (Mimosa scabrella Benth.) em bracatingais manejados e em florestas secundárias na região do planalto catarinense. Árvore, Viçosa, v. 35 , n. 4 , p. 845 - 857. 2011.

TONON, A. E. N. Efeito da Densidade Inicial e do Sítio Sobre o Crescimento e a Produção de Bracatingais da Região Metropolitana de Curitiba. 193 f. Dissertação (Mestrado em Ciências Florestais) - Setor Ciências Agrárias, Universidade Federal do Paraná. Curitiba, 1998.

URBANO, E.; MACHADO, S. A.; FIGUEIREDO FILHO, A.; KOEHLER, H. S. Equações para estimar o peso de carbono fixado em árvores de Mimosa scabrella Bentham (bracatinga) em povoamentos nativos. Cerne, Lavras, v. 14, n. 3, p. 194 - 203, 2008. 